\title{
Failure Studies on Adhesive Bonded and Bolted Joints of Natural Fiber Composites
}

\author{
Ayyappa ATMAKURI*, Arvydas PALEVICIUS**, Madhusudan SIDDABATHULA***, \\ Giedrius JANUŠSAS**** \\ *Kaunas University of Technology, Studentu 56, Kaunas, Lithuania, E-mail: ayyappa.atmakuri@ktu.lt \\ **Kaunas University of Technology, Studentu 56, Kaunas, Lithuania, E-mail: arvydas.palevicius@ktu.lt \\ ***Usha Rama college of Engineering, Andhra Pradesh, India, E-mail: Madhusudan_sunanda@rediffmail.com \\ ****Kaunas University of Technology, Studentu 56, Kaunas, Lithuania, E-mail: giedrius.janusas@ktu.lt \\ cross ref http://dx.doi.org/10.5755/j02.mech.28108
}

\section{Introduction}

The utilization of fiber-reinforced composite (FRC) materials gradually increased in industrial applications. The amounts of fiber composites used in modern aircraft surpass half of the vehicle weight [1]. It was also found that the usage of composites grater in the container ships, modern yachts, lightweight boats[2]. Even a greater share of composites has been using in automobile applications, approximately $50 \%$ of total vehicle volume [3]. Toyota automobile company first started using polymer composites to reduce the weight and increase the efficiency of the vehicle [4]. Since the metal components are and will be essential in these structures, the issue of linking composite and metal components becomes increasingly more significant as the portion of composite components in the structures increments. The joint utilized in a composite structure is typically the most sensitive part of the structure and consequently decides the primary efficiency [5]. The mechanical fastening (bolted joints) and adhesively bonded joining are the most popular ways of joining the fiber composites [6-7]. Despite joining methods and fabrication errors adhesive and bolted joints are used for both metal elements and fiber composites [8].

Most of the mechanical structures are consisting of numerous parts coupled together by a variety of joints, such as welded, adhesive, bolted, fastened, and bonded. These joints are the weakest portions of the composite structures because they establish the spots of possible damage initiation and failure [9]. So that, they required very keen and costly observation. In recent years, extensive research has been carried on the mechanical properties of adhesive joint composite materials [10-11] and bolted joint composite materials [12-13]. Joining the components also means a loss of continuity, which affects the performance and also reasons the damage of overall efficiency. The adhesive bonded composites were originally developed for several applications such as aerospace, automobile, construction, sports equipment, and shipping industries due to their excellent mechanical properties, low density, lightweight, and high thermal conductivity [14].

Kim J. et al. [15] experimentally investigated the surface treatments for carbon/epoxy composite adhesive joints and found the influence of various parameters on the failure behavior of composite bonded joints. They worked on plasma surface treatment, mechanical abrasion and sandblast treatment. Results stated that, the plasma treated joints all failed when the surface free energy was increased more than $40 \mathrm{mj} / \mathrm{m}^{2}$ and mechanically treated composites joints strength increased with optimal surface roughness and adhesive thickness. Huang H. et al. [16] developed an analytical model for estimating the stress and strain distributions of single-lap adhesive-bonded composite joints under tension. In FRC composite adhesive joints, according to the standard ASTM D5573. There is a total of seven modes of failure characterized by adhesive failure, cohesive failure, thinlayer cohesive failure, fiber-tear failure, light-fiber-tear failure, stock-break failure, or mixed failure. Analysis of singlelap adhesive composite joints with delaminated adherents has been carried out by Qin M. et al. [17] and Kim S. et al. [18] studied the failure modes and strength of pultruded FRP bolted connection members and predicted the failure strength using the results obtained by the experiment and the finite element analysis. Experimental tests have been conducted by Mara V. et al. [19] to investigate the effect of inserts on the stiffness, the load-bearing behavior of joints, and bolt-tension relaxation. Zhang et al. [20] investigated the influence of end distances on the failure of composite bolted joints and predicted failure patterns of bolted joints with different end distances, load-displacement curves, and failure loads and concluded that the results are in good agreement compared to experimental outcomes.

Wdowiak-Postulak [21] worked on the basalt fiber reinforcement of bent heterogeneous glued laminated beams. a bending test was performed, and stress properties under various load $(2.5-10 \mathrm{kN})$ were calculated inside the fibres (which were subjected to compression and tension), and the value were up to $40 \mathrm{MPa}$. Jakuba [22] worked on the effect of humidity-temperature cycling on carbon and aluminum fiber hybrid composites adhesive joints. Results showed that both aluminum and carbon fiber multi-layered adhesive joints showed a tensile strength ranging from 18 to $45 \mathrm{MPa}$ Stawski et al. [23] worked on thermal and mechanical properties of okra fiber composites obtained via various retting processes. The fibers extracted from the upper part of the plant have shown superior properties. Also, fibers that are obtained through the water retting process have shown superior properties. The authors have found a variation in thermal resistance. The reason can be the lack of chemical treatment of the fibers. Srinivasababu N. [24] investigated the tensile properties of various natural fiber composites. The results showed that an improvement in mechanical properties. Okra fiber composites showed superior properties to banana and sisal fiber composites.

With this motivation, in the present work, an attempt has been made to fabricate the okra and empty fruit 
bunch banana (EFBB) fiber reinforced polyester resin composites by using the hand-layup technique. India is one of the most widely cultivated countries for okra and banana plants. Okra fibers were extracted from these fruits and banana fibers were extracted from the empty fruit bunch of banana trees. Fibers were chemically treated before fabrication and to study their joint strength and failure phenomena under tensile load, flexural creep, and SEM analysis. The testing and comparative analysis were made for adhesive bonded and bolted joints.

\section{Composite fabrication}

\subsection{Materials}

The reinforcement and matrix materials used for the fabrication of composite samples are okra and EFBB fibers and polyester resin. The chemical composition and mechanical properties of okra and banana fibers are given in Table 1. NaOH solution was used for the chemical treatment process. The polyester resin along with the hardener was used as a binding material and it was purchased from ALGOL Chemicals India Private limited. The mould material made from natural rubber. Adhesive material and bolts were used for joining the composites.

Table 1

Properties of okra and banana fibers [25-27]

\begin{tabular}{|c|c|c|}
\hline Properties & Okra & Banana \\
\hline Cellulose content, $\%$ & $60-70$ & $60-65$ \\
\hline Hemi Cellulose, $\%$ & $15-20$ & $6-19$ \\
\hline Lignin, $\%$ & $5-10$ & $5-10$ \\
\hline Moisture, $\%$ & 12.67 & $10-11.5$ \\
\hline Pectic matter, $\%$ & $3-4$ & $3-5$ \\
\hline Youngs Modulus, $(\mathrm{GPa}$ & $3.2-12.8$ & $27-32$ \\
\hline Elongation, $\%$ & $2.5-8.6$ & $2.6-5.9$ \\
\hline Density,g/cm ${ }^{3}$ & $1.15-1.45$ & 1.35 \\
\hline Tensile strength, $\mathrm{MPa}$ & $52.6-233.8$ & $26.5-168.5$ \\
\hline
\end{tabular}

\subsection{Preparation of fibers}

After the extraction process, these fibers were allowed for the retting process and then beaten with the hammer. The obtained fibers were cleaned with water and dried to eliminate the moisture in them. The fibers were allowed for chemical treatment at $5 \% \mathrm{NaOH}$ solution and then washed with distilled water. The segregations are gently dispersed with hands sitting patiently. After separating them, fibers were looked over with a cotton checking outline for numerous times to isolate the fibers. The weight fraction of fibers considered for the fabrication of composite was as $5 \%, 10 \%$, and $15 \%$ of okra (OF_5, OF_10, OF_15) and EFBB (BF_5, BF_10, BF_15) fibers. In each fiber case, three types of composites were fabricated by varying the percentage of fiber content in it. Polyester resin along with the hardener was used as a matrix material. It was purchased from Sigma Aldrich. For proper resin solution, the weight proportions of both resin and hardener were considered a 10:1 ratio as per product instructions. The polyester resin and hardener were taken into a plastic vessel and mixed for 4-5 minutes at room temperature with a plastic stirrer until the mixture is uniform in color. Then, the solution is stirred for another 60 seconds to scrape the edges and bottom of the container. The adhesives and bolts (made up of plastic) were purchased from the local store to join the composites. The mechanical properties of polyester resin and hardener are given in Table 2 .

Table 2

Mechanical properties of polyester resin and hardener

\begin{tabular}{|c|c|c|}
\hline Properties & Polyester & Hardener \\
\hline Density,g/cm ${ }^{3}$ & $1.2-1.09$ & $0.97-0.99$ \\
\hline Viscosity at $25^{\circ} \mathrm{C}, \mathrm{MPa}$ & $250-350$ & 600 \\
\hline Tensile strength, $\mathrm{MPa}$ & $70.3-103$ & $33.5-70$ \\
\hline Youngs Modulus, $\mathrm{GPa}$ & 3.3 & 2.8 \\
\hline Mixing ratio & 10 & 1 \\
\hline Colour & Colour less & Brown \\
\hline Gel time & $25-36 \mathrm{~h}$ & $24-36 \mathrm{~h}$ \\
\hline
\end{tabular}

\subsection{Preparation of mould}

Natural rubber is the most widely used mould material because of its flexibility, cost-effectiveness, ease of use, and ability to reproduce. A rubber sheet mould of dimensions $160 \mathrm{~mm} \times 12.5 \mathrm{~mm} \times 3 \mathrm{~mm}$ was used for the fabrication of composites. The releasing agent was used for easy removal of the composite after the curing process and also it doesn't affect any mechanical properties.

\subsection{Fabrication of composite samples and joints}

The fibers were laid uniformly inside the mould before applying any resin to it. The polyester mixture has been poured over the fibers uniformly and compressed for a curing time of $24 \mathrm{~h}$, with a constant load of $6 \mathrm{~kg}$. Composites are fabricated at $23{ }^{\circ} \mathrm{C}$ and relative humidity of $28 \%$ by using ASTM D $638 \mathrm{M}$ standards. After fabrication the composites were placed in an oven for heat treatment process for $20 \mathrm{~min}$ at $60^{\circ} \mathrm{C}$ to eliminate the excess moisture in it and then joined together by using adhesives and mechanical fastening such as bolts to observe the joint strength. Before joining the composites, a suitable surface treatment was carried to clean and modify the surface of the sample to improve its bonding level. A sandpaper was used for surface treatment to achieve desired roughness on the surface of the composite specimens. The adhesive joining was accomplished by applying the thin layer of adhesive onto the composite surface. A natural glue was used as an adhesive for the bonding. For bolted joints, circle holes with a diameter of $4 \mathrm{~mm}$ were drilled in the centre of each composite specimen with a hand drilling machine at low speed to avoid surface disturbance. The fabrication process and testing of composites is shown in the following schematic diagram Fig. 1.

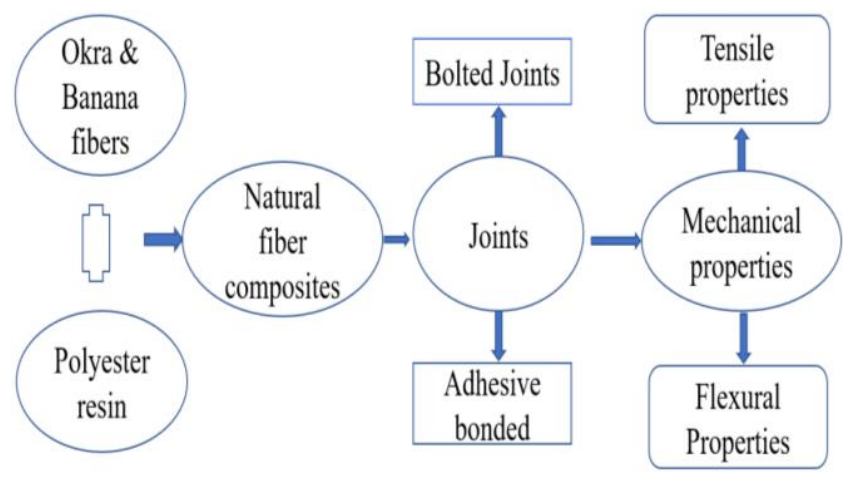

Fig. 1 Schematic diagram for fabrication and testing 


\section{Methodology}

\subsection{Tensile test}

Tensile tests were performed for both adhesive and bolted joint specimens to find out the joint strength of the composites. A total of five samples were tested for each composite and the dimensions are $80 \mathrm{~mm}$ length, $20 \mathrm{~mm}$ width and $5 \mathrm{~mm}$ thickness. The specimens were tested on Tinius Olsen $\mathrm{H} 10 \mathrm{~K}$ at a constant speed as $20 \mathrm{~mm} / \mathrm{min}$ and the dimensions were considered as per ASTM standards. The experimental setup used for the tensile test is shown in Fig. 2.

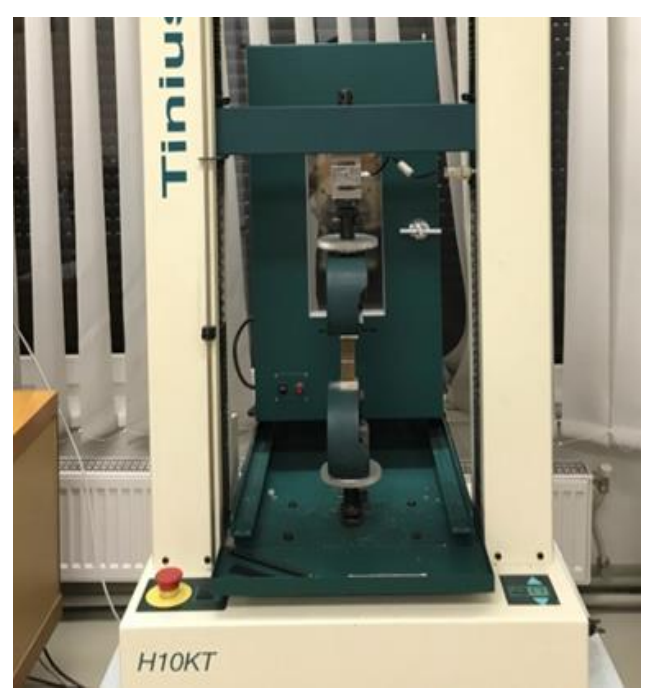

Fig. 2 Tensile test on Tinus Olsen H10KT

\subsection{Flexural creep test}

The flexural creep stiffness for both adhesive and bolted joints were measured at $2.5 \mathrm{~kg}$ and $5 \mathrm{~kg}$ of constant load. The setup used for the creep studies is showed in

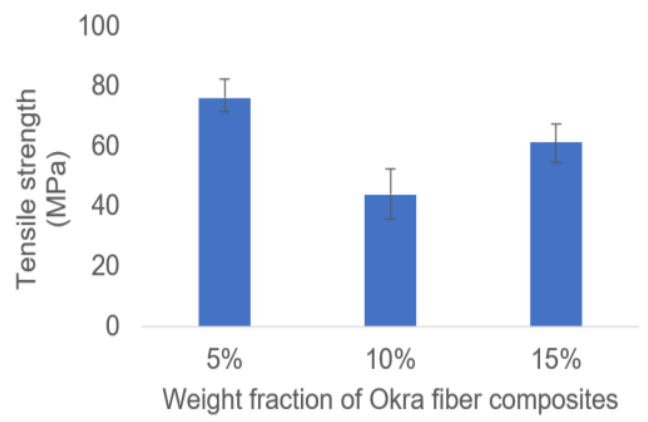

a
Fig. 3. The dimensions are $80 \mathrm{~mm}$ length, $20 \mathrm{~mm}$ width and $5 \mathrm{~mm}$ thickness. For each set of joints total of five samples were tested and the average values are reported. The values reported were for continuously four months (M1, M2, M3, M4) to observe the deflection.

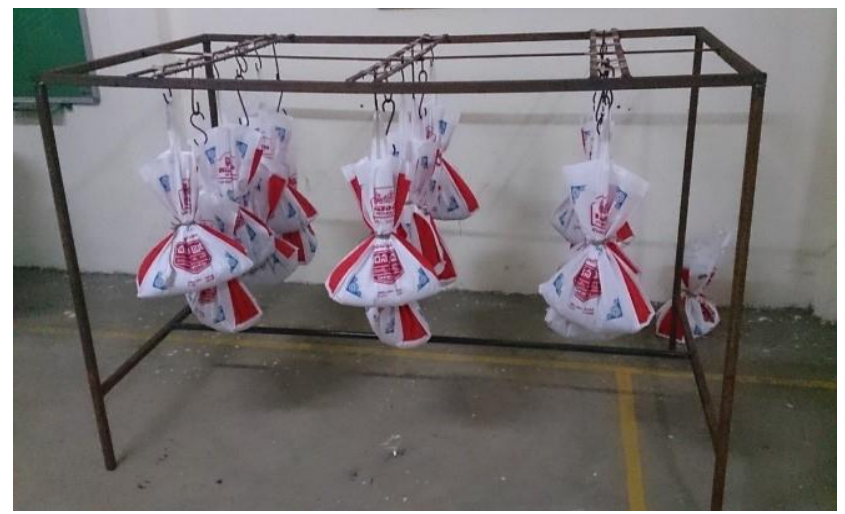

Fig. 3 Flexural creep test arrangement

\subsection{SEM analysis}

The failure studies of both okra and EFBB fiber adhesive joint fractured tensile test specimen were observed by using scanning electron microscope (S-3400N from Hitachi).

\section{Results and discussion}

\subsection{Tensile test for adhesive and bolted joints}

The tensile properties of adhesive and bolted joints for okra and EFBB fiber composites were tested on Tinius Olsen. All the samples were tested as per the standards and for each composite in total of five samples were tested. Three different fiber percentages (5, 10, and 15) and two types of joints namely adhesive and bolted were tested.

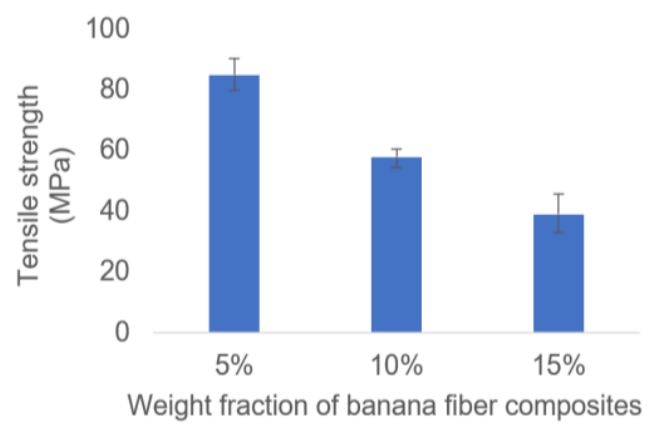

$\mathrm{b}$

Fig. 4 Tensile strength vs. weight fraction of okra fiber composites (a) and EFBB composites (b) adhesive-bonded joints

Fig. 4, a and $\mathrm{b}$ shows the tensile strength behaviour of the composites with $5 \%, 10 \%$, and $15 \%$ okra fiber and EFBB banana fiber composites with adhesive bonding. From Fig. 4, a the tensile strength values of okra fiber adhesive-bonded joint for $10 \%$ fiber composite are inferior as compared to $5 \%$ composite. $5 \%$ composite showed the joint strength as $76.13 \mathrm{MPa}$ whereas $10 \%$ composite showed $43.90 \mathrm{MPa}$. The reason for the above can be attributed in two ways. An increase in reinforcement content increases the strength of the composite. However, higher fiber content leads to the agglomeration of fibers, hence loss of strength.
Loss of adhesiveness at the interface might be another reason for lower joint tensile strength value. Upon increasing the fiber content $(15 \%)$ the values of joint strength (tensile) are higher as compared to $10 \%$ composites. This may be due to the combined effect of bonding at the interface and also higher fiber content. From Fig. 4, b, the tensile properties of EFBB composites are decreasing with the increase of fiber content. The joint strength for $10 \%$ and $15 \%$ composites are observed as $57.77 \mathrm{MPa}$ and $38.87 \mathrm{MPa}$ respectively. the joint strength depends on strength of the individual composite specimen as well as adhesive strength at the interface as explained earlier. 


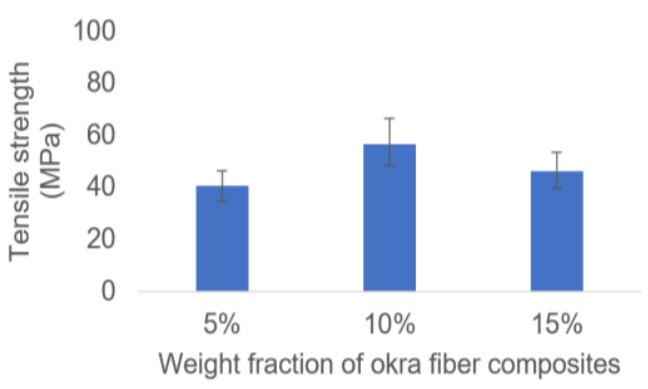

a

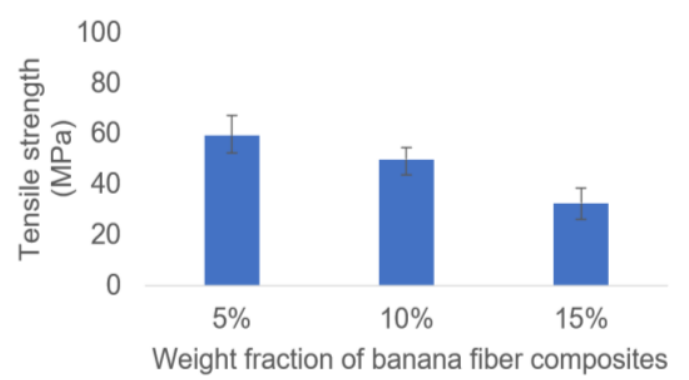

b

Fig. 5 Tensile strength vs. weight fraction of okra fiber (a) EFBB composites (b) bolted joints

Figs. 5, a and b shows the joint strength for okra and empty fruit bunch banana composites with varying weight fractions tested for bolted joint strength. From Fig. 5, a, it was observed that at 5\% reinforcement the tensile strength is low as compared to $10 \%$ and $15 \%$ fiber content. This trend supports the composite concept as reinforcement content increases, joint strength increases and hence improved bolted joint strength. Since the specimens joined by bolt the higher strength is obtained. Upon further increase in reinforcement content i.e., $15 \%$, the values are low as compared to $10 \%$ fiber content but higher than $5 \%$ fiber content. For inserting a bolt drilled hole is a prerequisite. It can be speculated that during drilling, fibers might have been separated or cut. This makes the specimen to lose its strength, hence a drop in joint strength. From Fig. 5, b, Joint strength is decreasing with increasing reinforcement content. This can be attributed to i) fibers might have lost the continuity while drilling a hole for fixing the bolt ii) there may be manufacturing defect like agglomeration/clustering, hence losing strength for the higher fiber reinforcement content.

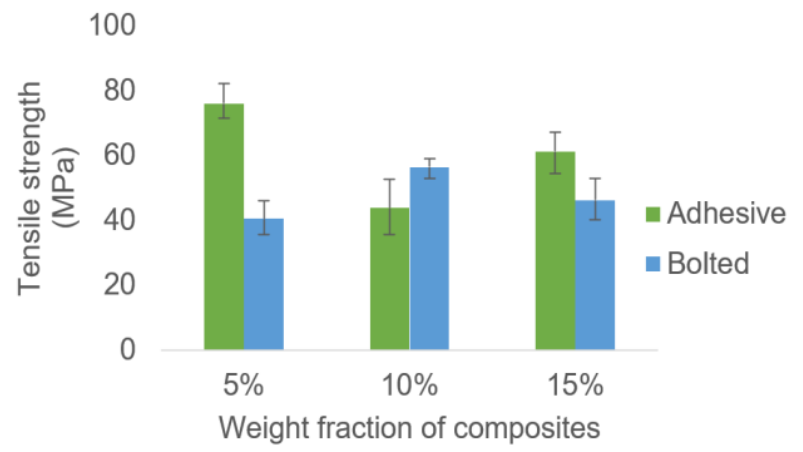

Fig. 6 Tensile strength of adhesive bond joint/bolted JointOkra fiber composites

Fig. 6 shows the comparison of bolted joint and adhesive joint strength values for $5 \%, 10 \%$, and $15 \%$ okra fiber composites. From the figure, it can be observed that except for $10 \%$ fiber composite, $5 \%$ and $15 \%$ adhesive bonded joints show superior joint strength values compared to bolted joints. The reason for the inferior joint strength for bolted joint may be due to the discontinuity or break up of fibers resulted due to drilling operation for fixing the bolt. The superior bolted joint strength for $10 \%$ composite could be due to drill or consequently bolt bypassing the fiber area or moving away from the fiber zone.

Fig. 7 shows the comparison of bolted and adhesive joint strength values for composites with fiber $5 \%$, $10 \%$, and $15 \%$ of EFBB. Both adhesive joint and bolted joint strength is decreasing with increasing fiber content. However, adhesive joint strength is superior as compared to bolted joint strength; the reason for the drop in joint strength for bolted joint has been explained in earlier paragraphs. The drop in joint strength for adhesive joint may be due to two reasons i) failure of adhesiveness at the interface (it is due to the curing time and conditions in the surroundings) ii) failure of the composite specimen due to manufacturing defects like poor bonding between the fiber and the matrix or clustering/agglomeration of fibers resulting in early failure. The agglomeration of fibers in the fabrication is mainly depends on the fabrication skills. In general, it is the most common error and the environmental conditions also play an important role to cause the defects in the composites.

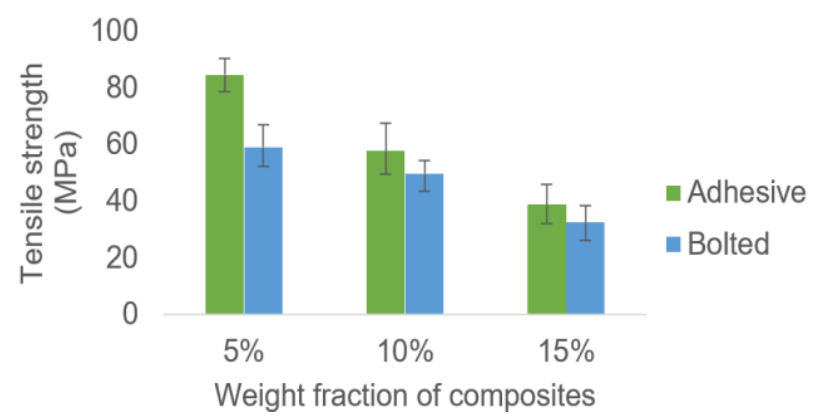

Fig. 7 Tensile strength of adhesive bond joint /bolted joint EFBB fiber composites

\subsection{Flexural creep test for adhesive and bolted joints}

Flexural creep tests were conducted on, both adhesive and bolted joints of okra/empty fruit bunch banana fiber composites. A three-point bending test was conducted to find out the deflection of both the joints at a constant load of $2.5 \mathrm{~kg}$ and $5 \mathrm{~kg}$. And the results were reported for continuous four months (M1, M2, M3, M4) period.

Figs. 8, a-c shows the flexural creep behaviour of okra fiber adhesive-bonded composites (5\%, 10\%, and $15 \%$ ) with time-variant. The flexural creep was observed at a constant load of $2.5 \mathrm{~kg}$ and $5 \mathrm{~kg}$ consecutively for four months. The deflection increases gradually from $1^{\text {st }}$ month to $4^{\text {th }}$ month in all the cases and also deflection was decreased with increasing fiber content. 5\% okra fiber adhesive joints showed superior deflection than $10 \%$ and $15 \%$ fiber joints. $10 \%$ okra composites showed much variation for $2.5 \mathrm{~kg}$ and $5 \mathrm{~kg}$ unlike $5 \%$ and $15 \%$ fiber adhesive joints.

The Flexural creep phenomenon for okra fiber bolted joint composites showed in Figs. 8, d-f. The deflection increased with respect to the time in all the cases. There was not much variation in the deflection for the $2.5 \mathrm{~kg}$ and 
$5 \mathrm{~kg}$ loading for bolted joints. It is due to 1) the adhesive bonded joints have greater strength and low structural

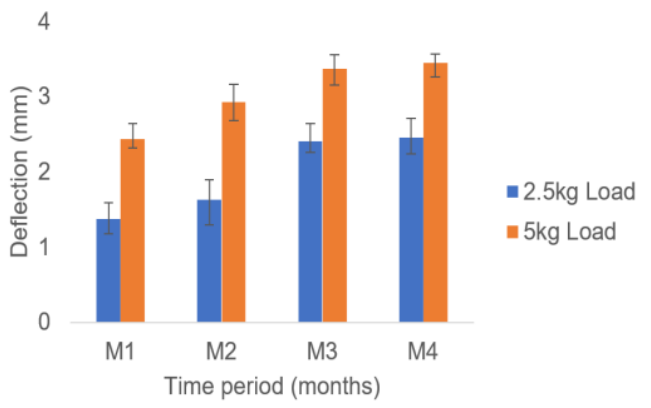

a) $5 \%$ Okra Adhesive

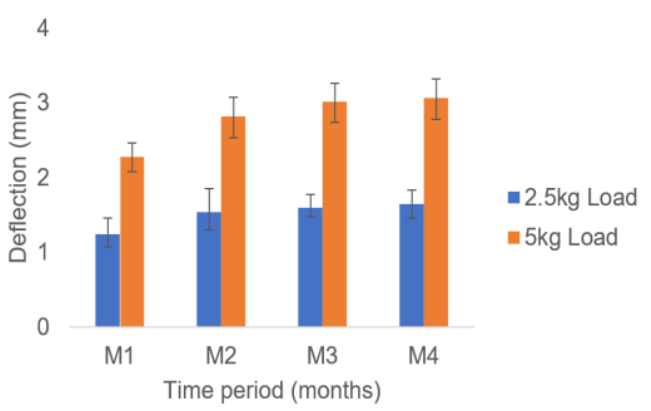

b) $10 \%$ Okra Adhesive

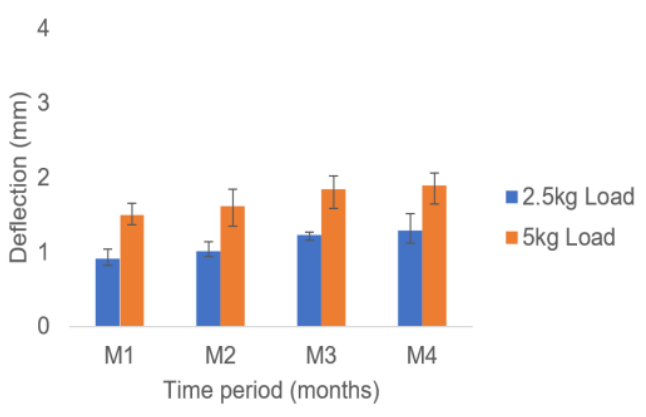

c) $15 \%$ Okra Adhesive weight when compared to the bolted joints 2) the load distribution is linear in the adhesive bonded joints whether it is nonlinear in the bolted joints.

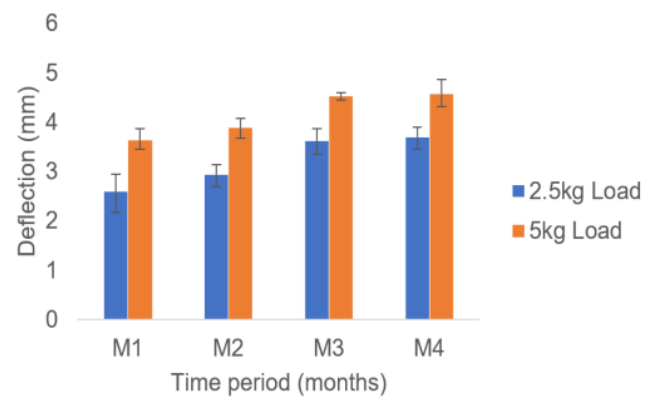

d) $5 \%$ Okra Bolted

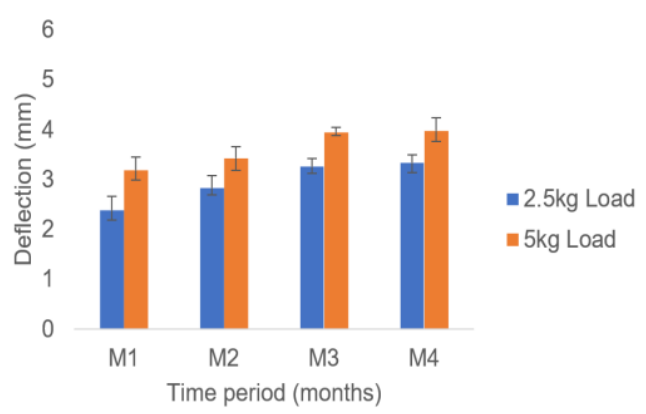

e) $10 \%$ Okra Bolted

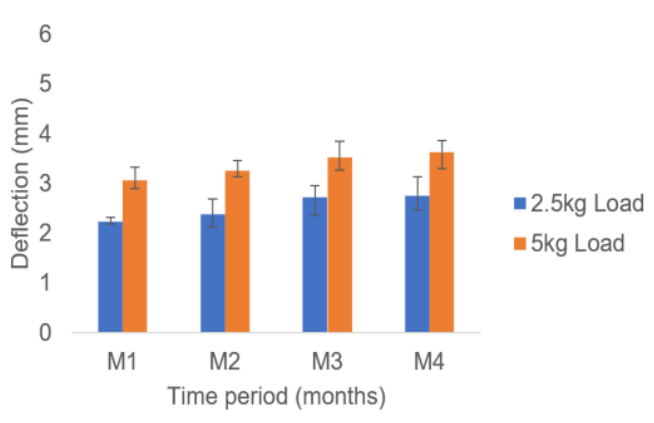

f) $15 \%$ Okra Bolted

Fig. 8 Deflection vs. Time for okra fiber adhesive bonded (a-c), and bolted joint (d-f) composites

Figs. 9, a-c shows the flexural creep behaviour of banana fiber adhesive-bonded joints with various weight fractions. From the above figure, it was observed that the deflection is increased with time and decreased with the increased fiber content. $5 \%$ of banana adhesive joints showed the highest flexural creep. The Flexural creep for banana bolted joints showed in Figs. 9, d-f. Results showed that the

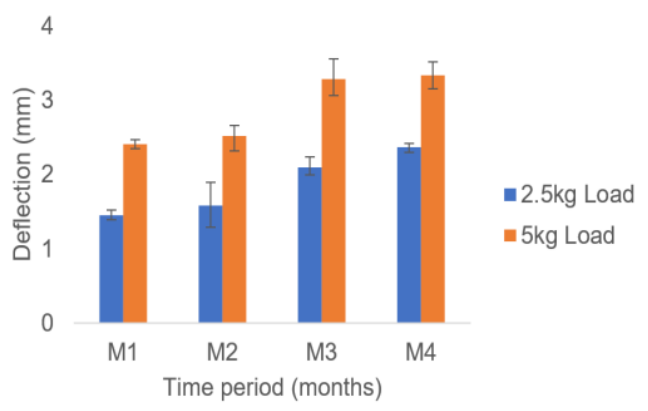

a) 5\% Banana Adhesive deflection is not much varied and it is unnatural. The reasons can be attributed to fabrication errors and deviation in drilling of composites for mechanical fastening. It was observed that the bolted banana fiber composites showed superior deflection than all other bonded joints. This means that bolted banana fiber composites possess less joint strength than others.

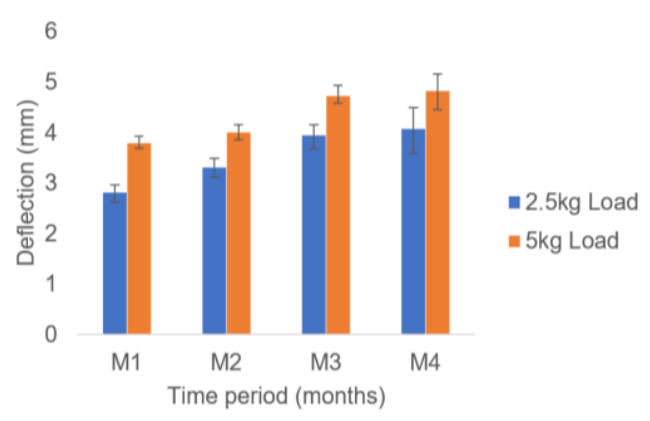

d) $5 \%$ Banana Bolted

Fig. 9 Deflection vs. Time for empty fruit bunch banana fiber adhesive and bolted joint composites 


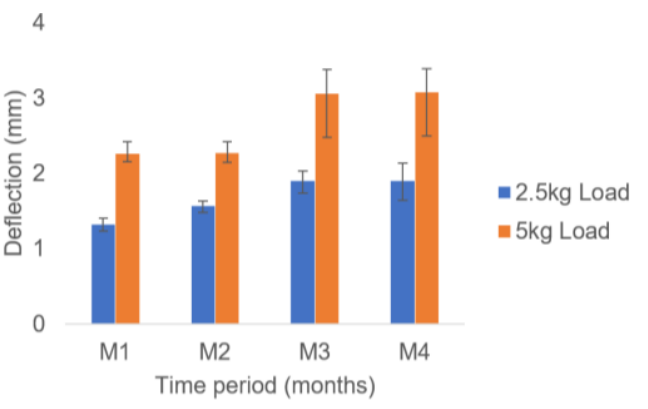

b) $10 \%$ Banana Adhesive

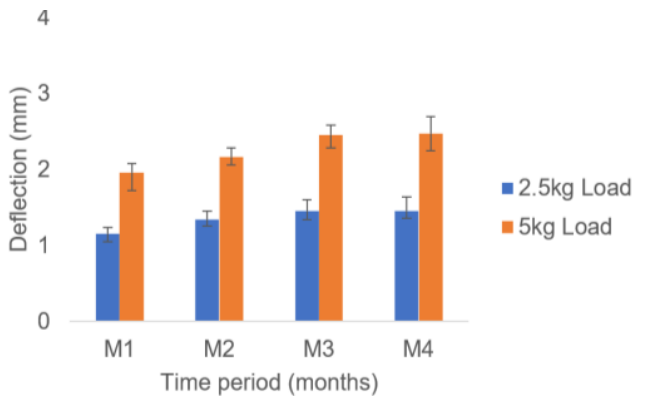

c) $15 \%$ Banana Adhesive

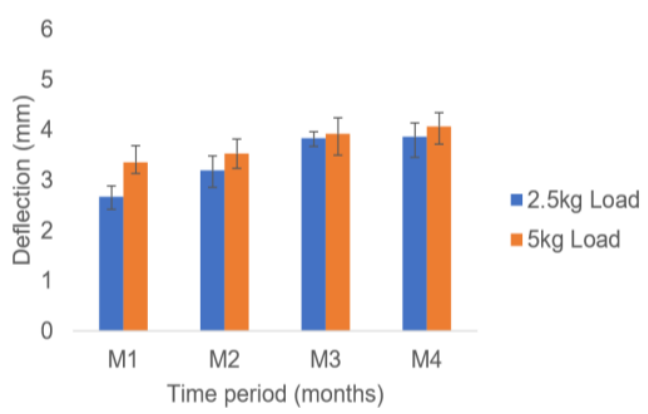

e) $10 \%$ Banana Bolted

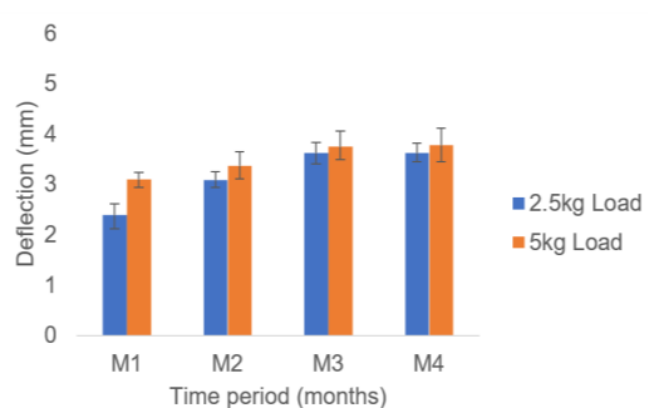

f) $15 \%$ Banana Bolted

Fig. 9 Continuation

Figs. 10, $\mathrm{a}$ and $\mathrm{b}$ shows the scanning electron microscope images for both okra and empty fruit bunch banana fiber adhesive-bonded tensile test fractured specimens. It was observed that both composites have internal defects such as the presence of voids, matrix cracks, internal cracks,

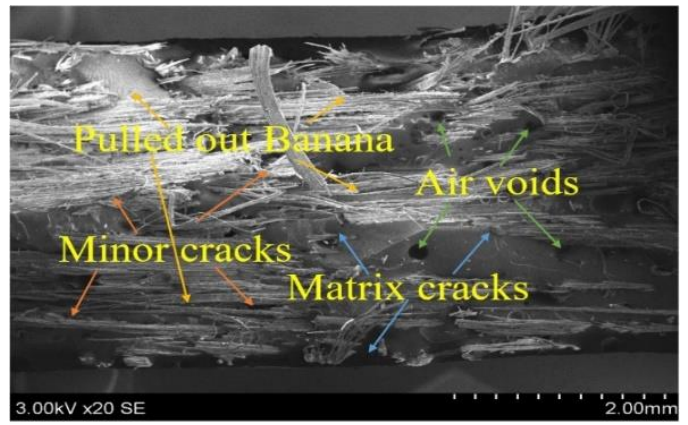

a

Fig. 10 SEM images for fractured Banana fiber

\section{Conclusions}

In this work, an attempt has been made to investigate the joint strength and failure studies under tensile load and flexural creep on natural fiber composites. Okra and empty fruit bunch banana fiber composites with varying weight fractions were fabricated by using the hand layup technique successfully. Empty fruit bunch banana fiber composites exhibited better joint strength properties under tensile loading when compared to the okra fiber composites. Okra fiber adhesive and bolted showed a range between 44 to $78 \mathrm{~N} / \mathrm{mm}^{2}$ and 40 to $60 \mathrm{~N} / \mathrm{mm}^{2}$ whereas empty fruit bunch banana fiber adhesive and bolted joints showed a range between 38 to $88 \mathrm{~N} / \mathrm{mm}^{2}$ and 42 to $68 \mathrm{~N} / \mathrm{mm}^{2}$ respectively. Higher fiber-reinforced composites have shown decreasing tensile strength as compared to the lower fiber content reinforced composites in both cases. Results showed that all the and adhesive material cracks. This is due to strong interfacial bonds between reinforcement and matrix material. It was observed that okra fiber adhesive joints have more defects compared to the empty fruit bunch banana joints due to the underprivileged bonding nature.

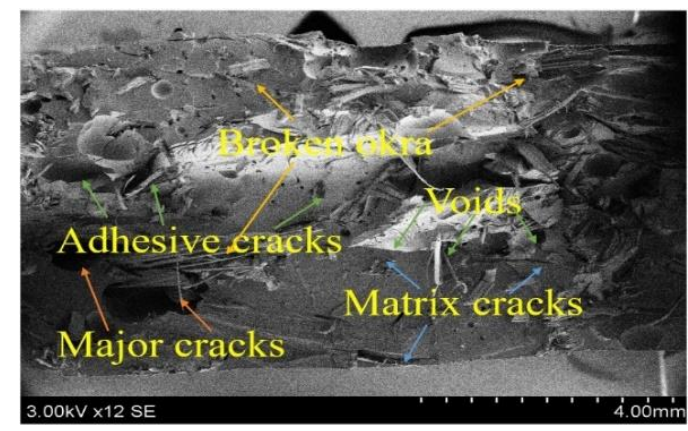

b

(a) Okra fiber (b) Adhesive tensile test specimens

joints responded to flexural creep. The deflection has increased with respect to the time and decrease of fiber content. Adhesively bonded joints responded to less creep than bolted joints. By enlarge, okra fiber composites exhibited less creep than banana composites. From SEM results, it was observed that both the composites have internal defects. Okra fiber composites have more defects than banana fiber composites it enhances to weaken the joint strength. Adhesively bonded joints possessing better sustainability as compared to the bolted joints in both cases. Apart from the manufacturing method of a specimen, the size of the bolt, location of the bolt, adhesive type, and weight fraction of fiber content in the composite will play a vital role in the joint strength. Okra fibers are a potential replacement for fiberreinforced composites for biomedical and lightweight applications. 


\section{Acknowledgement}

This research was funded by a grant S-MIP-19-43 from the Research Council of Lithuania.

\section{References}

1. Sheikh-Ahmad, J. Y. 2008. Machining of polymer composites. 1st ed. New York: Springer.

2. Rubino, F.; Nisticò, A.; Tucci, F.; Carlone, P. 2020. Marine application of fiber reinforced composites: a review, Journal of Marine Science and Engineering 8(1): $1-28$. https://doi.org/10.3390/jmse8010026.

3. Gardyński, L.; Caban, J.; Barta, D. 2018. Research of composite materials used in the construction of vehicle bodywork, Advances in Science and Technology Research Journal 12(3): 181-187.

https://doi.org/10.12913/22998624/92096.

4. El-Sheikhy, R.; Al-Shamrani, M. 2017. Interfacial bond assessment of clay-polyolefin nanocomposites CPNC on view of mechanical and fracture properties, Advanced Powder Technology 28: 983-992.

https://doi.org/10.1016/j.apt.2017.01.002.

5. Hassanifard, S.; Feyzi, M. 2017. Experimental and numerical investigation of fatigue damage accumulation in composite laminates, International Journal of Damage Mechanics 26: 840-858. https://doi.org/10.1177/1056789515625450.

6. Gray, P. J.; O'Higgins, R. M.; McCarthy, C. T. 2014. Effect of thickness and laminate taper on the stiffness, strength and secondary bending of single-lap, single-bolt countersunk composite joints, Composite Structures 107: 315-324.

https://doi.org/10.1016/j.compstruct.2013.07.014.

7. Chishti, M.; Wang, C. H.; Thomson, R. S. Orifici, A. C. 2012. Numerical analysis of damage progression and strength of countersunk composite joints, Composite Structures 94(2): 643-653.

https://doi.org/10.1016/j.compstruct.2011.08.030.

8. Jeevi, G.; Nayak, S.K.; Abdul Kader, M. 2019. Review on adhesive joints and their application in hybrid composite structures, Journal of Adhesion Science and Technology 33(14): 1497-1520. https://doi.org/10.1080/01694243.2018.1543528.

9. Gamdani, F.; Boukhili, R.; Vadean, A. 2019. Tensile behavior of hybrid multi-bolted/bonded joints in composite laminates, International Journal of Adhesion and Adhesives 95: 1-11. https://doi.org/10.1016/j.ijadhadh.2019.102426.

10. Guilpin, A.; Franciere, G.; Barton, L.; Blacklock, M.; Birkett, M. 2019. A Numerical and experimental study of adhesively- bonded polyethylene pipelines, Polymers 11: 1-16. https://doi.org/10.3390/polym11091531.

11. Ozel, A.; Yazici, B.; Akpinar, S.; Aydin, M. D.; Temiz, S. 2014. A study on the strength of adhesively bonded joints with different adherends, Composites Part B: Engineering 62: 167-174. https://doi.org/10.1016/j.compositesb.2014.03.001.

12. Hu, X. F.; Haris, A.; Ridha, M.; Tan, V. B. C.; Tay, T. E. 2018. Progressive failure of bolted single-lap joints of woven fibre-reinforced composites, Composite Structures, 189, 443-454. https://doi.org/10.1016/j.compstruct.2018.01.104.

13. Yazdani Nezhad, H.; Egan, B.; Merwick, F.; McCarthy, C. T. 2017. Bearing damage characteristics of fibrereinforced countersunk composite bolted joints subjected to quasi-static shear loading, Composite Structures 166: 184-192.

https://doi.org/10.1016/j.compstruct.2017.01.029.

14. Atmakuri, A.; Palevicius, A.; Vilkauskas, A.; Janusas, G. 2020. Review of hybrid fiber based composites with nano particles - material properties and applications, Polymers 12(9): 1-30. https://doi.org/10.3390/polym12092088.

15. Kim, J. K.; Kim, H.S.; Lee, D. G. 2003. Investigation of optimal surface treatments for carbon/epoxy composite adhesive joints, Journal of Adhesion Science and Technology 17(3): 329-352. https://doi.org/10.1163/156856103762864651.

16. Huang, H.; Yang, C.; Tomblin, J. S.; Harter, P. 2002. Stress and failure analyses of adhesive-bonded composite joints using ASTM D3165 specimens, Journal of Composites Technology and Research 24(2): 345-356. https://doi.org/10.1520/ctr10563j.

17. Qin, M.; Dzenis, Y. A. 2003. Analysis of single lap adhesive composite joints with delaminated adherends. Composites Part B: Engineering 34: 167-173. https://doi.org/10.1016/S1359-8368(02)00066-5.

18. Kim, S. Y.; Yoo, J. H. Kim, H. K.; Shin, K. Y.; Yoon, S. J. 2018. Failure modes of single and multi-bolted joint in the pultruded fiber reinforced polymer composite members. IOP Conference Series: Materials Science and Engineering 372: 1-7. https://doi.org/10.1088/1757-899X/372/1/012040.

19. Mara, V.; Haghani, R.; Al-Emrani, M. 2016. Improving the performance of bolted joints in composite structures using metal inserts, Journal of Composite Materials 50(21): 3001-3018. https://doi.org/10.1177/0021998315615204.

20. Zhang, J.; Liu, F.; Zhao, L.; Zhi, J.; Zhou, L.; Fei, B. 2015. Influence of end distances on the failure of composite bolted joints, Journal of Reinforced Plastics and Composites 34(5): 388-404.

https://doi.org/10.1177/0731684415572199.

21. Wdowiak-Postulak, A. 2020. Basalt fibre reinforcement of bent heterogeneous glued laminated beams, Materials 14(1): 1-19. https://doi.org/10.3390/ma14010051.

22. Korta, J.; Mlyniec, A.; Uhl, T. 2015. Experimental and numerical study on the effect of humidity-temperature cycling on structural multi material adhesive joints, Composite's part B: Engineering 79: 621-630. https://doi.org/10.1016/j.compositesb.2015.05.020.

23. Stawski, D.; Çalişkan, E.; Yilmaz, N.; Krucińska, I. 2020. Thermal and mechanical characteristics of okra (abelmoschus esculentus) fibers obtained via water- and dew-retting, Applied Sciences 10(15): 5113. https://doi.org/10.3390/app10155113.

24. Srinivasababu, N. 2009. Experimental determination of tensile properties of okra, sisal and banana fiber reinforced polyester composites, Indian Journal of Science and Technology 2(7): 35-38. https://doi.org/10.17485/ijst/2009/v2i7.8.

25. Cruz, J.; Fangueiro, R. 2016. Surface modification of natural fibers: a review, Procedia Engineering 55: 285288. 
26. Gholampour, A.; Ozbakkaloglu, T. 2020. A review of natural fiber composites: properties, modification and processing techniques, characterization, applications, Journal of material science 55: 829-892. https://doi.org/10.1007/s10853-019-03990-y.

27. Santulli, C.; Sarasini, F.; Fortunati, E.; Puglia, D.; Kenny, J. M. 2014. Okra fiber as potential reinforcement in the bio composites, Biomass and Bioenergy cham: springer international publishing, p.175-190. https://doi.org/10.1007/978-3-319-07641-6_11.

\section{A. Atmakuri, A. Palevicius, M. Siddabathula, G. Janušas}

\section{FAILURE STUDIES ON ADHESIVE BONDED AND BOLTED JOINTS OF NATURAL FIBER COMPOSITES}

\section{S u m m a r y}

Composites with natural fibers as reinforcements are playing a vital role in recent developments. The present work deals with the fabrication of okra and empty fruit bunch banana fiber polyester matrix composites with varying reinforcement content $(5 \%, 10 \%$, and $15 \%)$. Composites were fabricated by using the hand layup technique. After the fabrication process, composites were then adhesively bonded and also joined with bolts. The main objective of this work is to analyse the failure studies on adhesive bonded and bolted joints of okra and empty fruit bunch banana composite specimens. The specimens were tested under tensile load, flexural creep studies, and SEM analysis. It has been observed that empty fruit bunch banana fiber composites exhibited better joint strength properties under tensile loading when compared to the okra fiber composites. To estimate the flexural creep behaviour, all the samples were tested at a constant load of $2.5 \mathrm{~kg}$ and $5 \mathrm{~kg}$. The deflections obtained during regular time intervals (four months) were noted. The presence of internal defects and void content was observed by using the scanning electron microscope. The results showed that adhesive-bonded composites were exhibited less deflection compared to the bolted joints. The empty fruit banana fiber composites exhibited higher creep than okra fiber composites. Decreased creep with the increased fiber has been observed in both cases. SEM Adhesively bonded joints possessing better sustainability as compared to the bolted joints in both the fiber-reinforced composites.

Keywords: okra fiber composites, empty fruit bunch banana fiber composites, polyester resin, adhesive bonded joint, bolted joint, tensile strength, flexural creep, SEM.

Received December 03, 2020 Accepted October 04, 2021 